\title{
LIVRE-ARBÍTRIO E RESPONSABILIDADE A NATURALIZAÇÃO DA RESPONSABILIDADE DE P. F. STRAWSON
}

\author{
FREE WILL AND RESPONSIBILITY. P. F. STRAWSON'S NATURALIZATION \\ OF RESPONSIBILITY
}

\author{
RICARDO BINS DI NAPOLI ${ }^{1}$ \\ (UFSM,PUCRS - Brasil / LMU - Alemanha)
}

\begin{abstract}
Resumo
O objetivo do artigo é fazer uma nova análise da posição de P. F. Strawson sobre a relação entre livre arbítrio e responsabilidade moral, considerando a literatura recente sobre o tema. Parte-se, primeiramente, da relação entre liberdade e determinismo da ação. Em segundo lugar, analisa-se o texto de P. F. Strawson Liberdade e ressentimento, examinando sua proposta, referenciada na literatura recente como tendo dado uma contribuição fundamental para discussão do problema da responsabilidade, ao mostrar que as teorias da responsabilidade moral, teriam superintelectualizado as noções de responsabilidade, censura moral e culpa. Na conclusão é apontado que, por um lado, o referido texto teria mudado a abordagem do problema da responsabilidade através do seu conceito de atitudes reativas, por outro, essa noção de Strawson, deixando de lado uma metafísica da liberdade, tenderia a um tipo de naturalização da moral, presentes na teoria moral de E. Tugendhat e na proposta de A. N. de Brito.
\end{abstract}

Palavras-chave: Livre arbítrio; responsabilidade moral.

\begin{abstract}
The objective of this article is to make a new analysis of the position of the the position of P.F.Strawson concerning the relationship between free will and moral responsibility, taking into account the recent literature about the subject. We have to start, at first, with the relation between freedom and determinism of the action. Second, the famous text Freedom and Ressentment by P.F. Strawson has to be analised, examining his proposal mentioned in a recent literature as having given a fundamental contribution for the discussion of the problem of responsibility, when showing that the theories of moral responsibility would have been over intelectualized the notions of responsibility, moral censorship, and guilt. At the conclusion it is pointed out that, on one hand, the text mentioned would have changed the approach of the problem of responsibility through its concept of reactive attitudes; on the other hand, this notion of Strawson, leaving aside a metaphysics of the freedom, there would be a tendency to one kind of naturalization of the morality present in the moral theory of E. Tugendhat and in the proposal of A.N. de Brito.

Key words: free will; moral responsibility
\end{abstract}

\section{Introdução}

O conceito de livre-arbítrio (ou liberdade de deliberação) vem sendo discutido na relação com o determinismo da ação. Entre as possibilidades de pensar essa segunda relação, estão o compatibilismo e incompatibilismo. O compatibilismo é a posição que pretende mostrar que o livrearbítrio é perfeitamente compatível com o determinismo ${ }^{2}$. Para essa posição, mesmo para o caso de o determinismo ser verdadeiro, será possível imputar responsabilidade a agentes, não afetando 
a moral. Já o incompatibilismo defende que, se o determinismo for verdadeiro, não haverá livrearbítrio, consequentemente não haverá nada pelo qual uma pessoa possa ser considerada moralmente responsável.

Em face das alternativas compatibilistas e incompatibilistas, o objetivo deste artigo é repensar a análise de P. F. Strawson sobre a relação entre o livre-arbítrio e a responsabilidade moral, considerando a literatura recente sobre o tema. Para alcançar o objetivo proposto, é fundamental analisar o texto de P. F. Strawson, Liberdade e ressentimento, examinando criticamente sua proposta, em face das alternativas anteriores (compatibilista e incompatibilista). A teoria proposta por Strawson nesse texto é referenciada, na literatura recente, como tendo dado uma contribuição fundamental para discussão do problema da responsabilidade, ao mostrar que as teorias da responsabilidade moral, sejam as consequencialistas, sejam as meritocráticas, teriam superintelectualizado as noções de responsabilidade, de censura moral e de culpa. Além disso, o referido texto de Strawson, por um lado, teria mudado a abordagem do problema da responsabilidade por meio do seu conceito de atitudes reativas (Eshleman, 2004; Williams, 2006). Nesse sentido, para ele, um indivíduo ser responsável significa ser capaz de ter atitudes reativas em relação aos demais, tais como o ressentimento, a censura, a admiração e a gratidão. O determinismo, por outro lado, se verdadeiro, não teria influência sobre as atitudes que temos uns em relação aos outros. Elas estão tão enraizadas na nossa natureza, que seria impossível psicologicamente abandoná-las.

Do meu ponto de vista, a noção de Strawson tende a salientar o papel dos sentimentos humanos sobre os elementos racionais na moral presentes na nossa vida social e na nossa psicologia moral. Com isso, penso, que o aspecto mais relevante na sua teoria moral ainda seria o fato de Strawson ter produzido uma espécie de naturalização da moral ${ }^{3}$, pois os sentimentos morais seriam a base natural dos seres humanos para estabelecer os comportamentos moralmente aceitáveis e os censuráveis.

Esta idéia me parece bastante aceitável e importante, na medida em que aproximaria as especulações filosóficas com os novos estudos da biologia evolucionista da moral e da neurociência. Com isso, gostaria de chamar à atenção as tentativas que E. Tugendhat e Adriano Brito vêm procurando fazer ${ }^{4}$. Abordarei, em primeiro lugar, os conceitos de livre-arbítrio e responsabilidade. Em segundo lugar, apresentarei as principais ideias de Strawson no famoso artigo de 1962. Concluirei indicando alguns elementos da teoria de Tugendhat e das análises de Adriano N. de Brito que, a meu ver, se aproximam, de certa forma, da perspectiva strawsoniana.

\section{Livre-arbítrio e responsabilidade}

O livre-arbítrio e a responsabilidade moral são conceitos relacionados. A responsabilidade, em geral, é definida no sentido de imputação. Ser responsável implica, primeiro, em poder ter 
tomado uma decisão livremente, independentemente de coerção externa. Sendo-se livre, pode-se decidir. Ao decidir agir contrariamente ao que é considerado moralmente correto, o agente pode ser objeto da crítica dos demais. Ao agir corretamente, o agente é digno de louvor. Por isso, diz-se que ele merece a crítica ou o louvor. Essa é a razão para se dizer que a imputação de responsabilidade é uma questão de merecimento ou de mérito.

O livre-arbítrio também pode ser tratado intuitivamente a partir do conceito de liberdade. Percebe-se que o conceito de liberdade exige uma consideração metafísica. A metafísica da liberdade, como afirmava já Hume, é uma das questões mais difíceis da filosofia e implica em considerar as ações humanas como parte do mundo. O problema metafísico que emerge dessa perspectiva de descrição é que o agente humano surge como um indivíduo determinado por leis que governam o próprio mundo, sejam elas de natureza física, biológica ou sócio-cultural. Disso decorre o paradoxo de que o homem parece objetivamente determinado, mas subjetivamente ele se pensa como decidindo o que fazer. Assim, da perspectiva subjetiva o homem parece livre, escolhendo e tomando decisões, enquanto da perspectiva objetiva, determinado.

Por livre-arbítrio se entende normalmente a capacidade do indivíduo deliberar livremente. Deliberar livremente foi uma condição já apontada por Aristóteles, denominada por "agir voluntário". Age voluntariamente aquele que age segundo um princípio que se encontra nele mesmo, independentemente de fatores como a compulsão ou a ignorância, que possam impedir essa deliberação e escolha (1110a15-20). Ainda que um pouco obscura, essa definição de Aristóteles enfatiza que o homem deve conhecer o que faz e escolher seus atos por ele mesmo (1105a15-1105b).

Também em Kant vamos encontrar uma definição de liberdade prática que se relaciona com a nossa capacidade de agir segundo a representação de leis universais, válidas para todos os seres racionais. Agir segundo imperativos morais para Kant torna o homem livre e, portanto, passível de responsabilização, tanto quanto para Aristóteles os atos voluntários podem ser imputados a um agente.

Nessa tradição, é possível também dizer que a responsabilidade pode ser imputada a um agente se ele agiu em determinadas condições, ou seja, se teve liberdade de escolha racional. Kant, entretanto, exige mais que uma deliberação racional com vista a um fim definido pelo agente, ou seja, ele defende que a pura racionalidade do agente é capaz de determinar não só seus juízos sobre si e os demais, mas também a sua ação. Ele exige, para que os atos possam ser denominados de livres, que os atos sejam praticados segundo uma regra que possa ser aceita universalmente por agentes racionais. Em outras palavras, Kant acopla à condição de racionalidade de uma regra o fato de que ela deva ordenar universalmente e não segundo a prudência, o interesse do agente ou seus desejos e suas emoções. Esse tipo de característica da ação Kant chamou de liberdade enquanto autonomia.

Contudo, a liberdade prática motivada independentemente de qualquer condição natural 
de nossa psicologia ou sociabilidade está indissoluvelmente ligada, para Kant, "a um conceito não empírico ou 'transcendental da liberdade' (...)” (Almeida, 1997, p.175). Essa ideia significa que a liberdade é "uma propriedade que teria uma causa de iniciar uma série de eventos, sem ser determinada a isso por nenhuma ocorrência anterior e, por conseguinte, determinando-se a isso por si mesma" (Almeida, 1997, p. 178).

Posteriormente, essa condição metafísica da liberdade da ação foi rebatizada de "liberdade contra causal", uma vez que, para Kant, a liberdade exige que, se se deve fazer algo, pode-se fazê-lo ou não, dependendo apenas de nossa escolha. Assim, é exigido no mínimo que, para o cumprimento de um dever moral, possa fazê-lo livremente (ver Frankena, 1963, p. 84-85). Esse é o denominado "princípio Kant”. Mas se alguém não pode fazer algo, então não se pode exigir que ele ou ela tenha tal obrigação. Isso sugere que, uma vez tomada uma decisão, sempre se possa ter tido a oportunidade de não ter seguido tal obrigação, mas sim uma outra. Como já afirmei, a liberdade prática exige a condição de uma liberdade transcendental, que diz que sempre, independentemente de determinações anteriores, podemos iniciar uma nova cadeia causal.

Relacionando, então, a noção essa noção de liberdade a de responsabilidade, entender-se-ia a responsabilidade como a possibilidade de atribuirmos a um agente a causalidade de uma ação e suas consequências. Mas em que sentido fala-se aqui de causalidade? Novamente surge a questão metafísica, com a pergunta sobre a verdade ou falsidade do determinismo. Mas a verdade ou falsidade diria respeito, para Kant, a uma questão de conhecimento. Por isso, a tese do determinismo/ liberdade que extrapola os limites do conhecimento, podendo ser apenas tratada como uma ideia da razão, assim como as questões sobre imortalidade da alma e a da existência de Deus. A liberdade, para Kant, é definida como uma espécie de causalidade do agente racional, diferente da causalidade natural. Ele teve que admitir, para salvar a moralidade do determinismo, uma segunda forma paralela aos motivos empíricos. Essa nova causalidade é racional, porque permite aos agentes a autodeterminação. Assim, pode-se entender a posição compatibilista de Kant: a causalidade, no plano sensível, pode ser compatível com outra causalidade no plano inteligível. A liberdade do agir é compatível com a causalidade da natureza.

Como foi dito no início, os deterministas acham que o determinismo é verdadeiro, e os indeterministas pensam contrariamente. Entre os deterministas, há os que consideram o determinismo compatível com a liberdade - esses são denominados de compatibilistas. Os que consideram o determinismo incompatível com a liberdade são chamados de incompatibilistas.

Mas por que falar ainda em uma metafísica da liberdade ou do livre-arbítrio em uma era de desenvolvimento científico acelerado? Será que a ciência não nos trouxe nenhum novo conhecimento para que se pudesse tratar essa questão em novas bases? Devemos continuar a trabalhar em ética com um conceito de liberdade que implica sempre tal metafísica? Não seria já hora de sofisticarmos nosso aparato conceitual para tratarmos do problema no século XXI? 
Estas mesmas análises do conceito de responsabilidade julgam, então, que P. F. Strawson, com seu famoso artigo Freedom and resentment (1962), teria introduzido uma virada no modo como tradicionalmente se vinha pensando a questão da relação entre o livre-arbítrio e a responsabilidade. A tese de Strawson seria contrária a ambas as teorias, as quais teriam superintelectualizado a responsabilidade, pois assumem que "a racionalidade de tomar uma pessoa como responsável depende de um julgamento de que a pessoa em questão satisfez algum conjunto de requisitos para ser responsável (condições de eficácia e liberdade metafísica) e que esses requisitos são justificáveis" (Ehleman, 2004).

\section{A análise de Strawson: otimistas vs pessimistas}

A tese de Strawson, a meu ver, é de que a nossa capacidade moral está enraizada na natureza interpessoal de nosso modo de vida, não permitindo uma justificação racional externa ao contexto relacional dos agentes, pensados como agentes sociais, racionais e falantes. Por isso, pode-se defender, com P. Smith (1992), que Strawson buscou uma naturalização do conceito de responsabilidade. Sua tese implica que a responsabilidade não é mais tematizada por meio dos conceitos de liberdade e de consciência, presentes na deliberação do agente moral. Com isso, Strawson possibilita deixar de lado a discussão metafísica da liberdade/determinismo De fato, Strawson afirma isso (1974, p. 23), embora ele não identifique seus oponentes de forma tão clara.

Quem são de fato os dois partidos identificados por Strawson que estariam em polos opostos na discussão sobre o determinismo? Em princípio, Strawson identifica basicamente duas posições antagônicas: os pessimistas e os otimistas. Diz que, para os primeiros, "se a tese do determinismo é verdadeira, os conceitos de obrigação moral e responsabilidade realmente não têm aplicação e as práticas de punição, condenação e aprovação são realmente injustificadas"; para os otimistas, “os conceitos e as práticas de modo algum perdem sua raison d'être, se a tese do determinismo é verdadeira" (Idem, p. 1). Fica a ser decidido pelo leitor quem são exatamente os filósofos representativos dos dois partidos. Strawson, entretanto, retoricamente, se identifica com um partido que não saberia qual exatamente é a tese do determinismo.

Contudo, além desses partidos, dever-se-ia pensar o partido dos céticos, que duvidam da liberdade moral. Para esses céticos, sendo o determinismo verdadeiro, em primeiro lugar, os conceitos de obrigação moral e de responsabilidade perderiam sua aplicação, como o próprio Strawson apresenta os pessimistas (1974, p. 1). Mas o "cético genuíno" seria aquele para o qual "as noções de culpa moral, condenação e responsabilidade são inerentemente confusas e se pode ver que são de fato, se nós consideramos tanto a verdade como a falsidade do determinismo" (1974, p. 1). Em segundo lugar, as práticas de punição e censura, bem como as expressões de condenação moral ou aprovação seriam injustificadas. Em todo o seu texto, Strawson tem o objetivo de atacar o que ele 
chama de pessimistas e, de certo modo, também o outro grupo, que ele chama de "os otimistas" (1974, p. 1, 23).

Em um debate, como argumentariam otimistas e pessimistas? Strawson reconstrói o suposto debate imaginário com o objetivo de ver se seria possível uma conciliação entre as duas posições. Para ele, seria preciso o recuo de um dos lados, a fim de que a outra posição pudesse fazer uma concessão substancial.

Em outras palavras, o otimista acredita que a eficácia das práticas de punição e de condenação ou aprovação moral regulam nosso comportamento social de modo desejável (1974, p. 2). Embora a eficácia dessas práticas não prove que o determinismo seja falso, Strawson pondera que, se o otimista percebe que perde algo vital, o pessimista nota que, ao querer esse algo vital, ultrapassa os fatos além do que se pode conhecer, provavelmente, penso eu, por não ter certeza do determinismo. Strawson pergunta então: não deveria o pessimista dar um passo atrás fazendo uma concessão? Mas essa suposta concessão argumentativa do pessimista que Strawson parece indicar não é muito clara no texto, inicialmente. Na parte dois do texto, Strawson avança o debate um pouco mais. Vejamos um pouco mais.

Para os pessimistas, se há eficácia das punições e da condenação moral, então há culpa moral. Esta, por sua vez, implica em responsabilidade moral, que, por sua vez, implica em conceber a liberdade de ação. Mas tal conclusão implicaria igualmente a falsidade do determinismo. Em outras palavras, diriam os pessimistas que os otimistas prefeririam que a tese do determinismo fosse verdadeira, para afirmar a tese da eficácia moral das práticas. Assim, os conceitos morais também fariam sentido.

Os otimistas argumentariam dizendo que a verdade das práticas requer, sim, uma noção negativa liberdade, isto é, a ausência de certos impedimentos do agente, tais como compulsão, incapacidade inata, insanidade ou outras formas menos extremas de "desordem psicológica", ou a existência de circunstâncias da ação que fizessem com que o agente ficasse limitado em sua condição de liberdade. Em conseqüência, a condenação de agente e sua punição só seriam apropriadas se o agente estivesse submetido a uma restrição de liberdade.

O pessimista poderia conceder que a existência de uma liberdade em sentido negativo seria compatível com a tese do determinismo (Strawson, 1974, p. 3). Mas se uma punição faz sentido, ela precisaria ser merecida. Isso, para o pessimista, requereria mais do que apenas condições atenuantes para a imputação moral. Em outras palavras, merecimento da punição implica identificação do conceito de vontade com o ato, ou seja, uma noção de liberdade no sentido positivo, ou ainda, liberdade como autonomia da vontade. Contudo, a liberdade positiva, para Strawson, seria, sim, incompatível com a tese do determinismo. Penso que isso só seria possível, por exemplo, se se entendesse Kant como incompatibilista; mas penso, ao contrário, que, defendendo o conceito de liberdade positiva, Kant é um compatibilista. 
O otimista poderia avançar mais um argumento dizendo que todas as pessoas decidem coisas e dão razões para o que fazem. Não se seguiria, segundo ele, a tese do determinismo, segundo a qual ninguém decide nada, ninguém não faz nada intencionalmente. $\mathrm{O}$ fato de o pessimista trazer o conceito de liberdade positiva não implica a negação da liberdade em nenhum sentido, muito menos a negação do determinismo ${ }^{5}$ (Strawson, 1974, p. 4).

Strawson diz, ainda, que o pessimista identificaria uma lacuna no raciocínio do otimista, a saber: que os conceitos de liberdade não seriam postos em questão pela tese do determinismo. De fato, o único argumento apresentado pelo otimista foi o da eficácia das práticas de condenação moral e punição do agente. Esse argumento não seria suficiente para justificar as práticas morais e o uso significativo de conceitos morais (Strawson, 1974, p. 4).

Eu poderia, por um lado, concordar com o pessimista, dizendo que o otimista deveria apresentar boas razões para a condenação moral. Mas, certamente, se o pessimista admite o compatibilismo, pois diz que não tem problemas em aceitar as liberdades, como parece ser o caso agora, ele não se mantém coerente com sua tese inicial, qual seja, de que, sendo verdadeiro o determinismo, os conceitos não têm sentido e as práticas não têm justificação. Por outro lado, parece que o pessimista, dando um passo atrás, isto é, aceitando a noção de liberdade negativa e dizendo que mesmo o conceito de liberdade positiva não afetaria a tese do determinismo, deixou o otimista em situação difícil: a de justificar melhor por que devemos aceitar a condenação moral e a punição, para além de sua mera eficácia. Isso é considerado por Strawson como uma verdadeira lacuna no argumento do otimista.

Após essa exposição das teses das partes, a pergunta seria: aonde quer Strawson levar o leitor, já que, nas partes subseqüentes $(3,4,5)$, quer apresentar sua teoria sobre o relacionamento moral, conhecida como teoria das atitudes reativas? A sua indagação sobre a possibilidade de conciliar o partido dos pessimistas com o dos otimistas e a resposta que o otimista deveria dar ao pessimista sobre a justificação das práticas de condenação e punição, que só serão retomadas no final do texto (parte 6), deveria ser respondida. Antes, contudo, deve-se entender a tese de Strawson sobre as atitudes reativas e a responsabilidade.

\section{A tese de Strawson}

Será que de fato Strawson busca uma conciliação entre os partidos? Será que ele endossa a tese do pessimista (determinista duro), ou procura salvar o otimista de uma banalização da justificativa para a moral? Será que a eficácia social da moral seria uma boa razão para continuarmos usando tais conceitos e praticando atitudes de louvar e condenar? Ou, ainda, que sentido fazem as perguntas iniciais de Strawson, quando analisa as atitudes reativas?

Para responder a essas perguntas, pode-se adiantar que, no seu texto de 1962, Strawson de 
fato procura vincular a moralidade e sua prática à capacidade psicológica do homem de reagir às atitudes dos demais indivíduos com quem se relaciona, seja condenando ou elogiando suas atitudes. Essa estratégia leva a uma naturalização da discussão a respeito da responsabilidade moral, desvinculando-a da indagação sobre a existência do livre-arbítrio.

Strawson quer chamar a atenção, em primeiro lugar, para um lugar comum, que a filosofia contemporânea em seu estilo "cool" (1974, p.6) costuma esquecer: o fato de que o homem se importa com as atitudes e intenções dos outros em relação a ele e que seus sentimentos e reações pessoais dependem de suas crenças sobre esses mesmos sentimentos ou envolvem esses mesmos sentimentos e reações (1974, p. 5). Assim, os sentimentos de benevolência, respeito e estima, que se opõem aos sentimentos de malevolência, indiferença e desprezo, contribuiriam para que o homem entendesse melhor suas crenças sobre as atitudes dos outros em relação a ele e outros. Se, por exemplo, alguém nos pisa o pé com um sentimento pertencente a um dos dois grupos mencionados acima, formamos uma crença a respeito do tipo de relação que essa pessoa está tendo conosco: se estima ou desprezo. Também o ressentimento e a gratidão formariam um bom par de sentimentos para nos mostrar coisas semelhantes.

Essas atitudes são chamadas por Strawson de atitudes reativas. Strawson salienta as duas principais atitudes reativas: o ressentimento e a indignação ou desaprovação moral (1974, p.14). O ressentimento se refere ao sentimento de uma pessoa diante de uma injúria praticada contra ela. A indignação diz respeito a uma "reação a uma qualidade da vontade de outros, não para conosco, mas contra outros" (Strawson, 1974, p.14). "Aquele que experiencia o análogo vicário do ressentimento é dito ser o indignado" no sentido moral. É vicário porque a injúria praticada contra outrem ou a atitude de indiferença para com alguém pode ser assumida por qualquer pessoa que perceba o caráter imoral de uma ação. Por isso tem um aspecto imparcial ou desinteressado ou generalizado, diz Strawson (1974, p. 14). As formas generalizadas ou vicárias das atitudes reativas pessoais baseiam-se nas mesmas expectativas e demandas da forma pessoal, mas dirigem-se a todos em nome dos quais a indignação moral é sentida (1974, p. 15).

Um aspecto importante, destacado por Strawson, é o fato de que as formas diferentes das atitudes reativas são conectadas humanamente e não logicamente. Elas devem ser vistas de três perspectivas: 1) as demandas que são feitas aos outros; 2) as reações dos indivíduos às possíveis ações injuriosas dos outros, e 3) as nossas autorreações associadas às demandas dos outros para conosco. Essas últimas, então, expressam o sentimento de comprometimento ou obrigação (senso de obrigação), o sentimento de culpa ou remorso ou, finalmente, o sentimento de responsabilidade, incluindo o fenômeno da vergonha 7 . "Em geral, diz Strawson, embora dentro de limites, nós demandamos de umas pessoas para outras, tanto quanto de nós para os outros, aquilo que demandamos de outros para nós mesmos”. Por essa razão, para Strawson, essas três atitudes sempre estão juntas e "têm suas raízes comuns na nossa natureza e em nosso pertencimento a comunidades humanas".

Strawson introduz também o termo atitudes reativas pessoais. Essas "baseiam-se e refletem 
uma expectativa e uma demanda por algo; manifestação de certo grau de boa vontade ou atenção da parte de outros seres humanos em relação a nós mesmos; ou pelo menos a expectativa de, e demanda por uma ausência de manifestação de uma vontade má (ill) ou desatenção indiferente (indifferent disregard)". Alguém poderia confundir as atitudes com juízos morais. Entretanto, penso que os juízos têm base racional, as atitudes, ao contrário, repousam sobre sentimentos e, por isso, têm bases emocionais ${ }^{8}$.

Strawson afirma que as atitudes reativas expressam nosso compromisso para com os outros. Esse compromisso, diz ele, "é parte de nosso quadro geral da vida humana, não algo que surge para uma revisão como os casos particulares que surgem para a revisão nesse quadro geral” (1974, p. 13). Além disso, ele escreve que dependemos desse compromisso na nossa vida ordinária de relacionamento com os outros (1974, p. 11). O compromisso perpassa eficazmente e está profundamente enraizado em nós; por isso, estar envolvido em relacionamentos pessoais significa justamente "estar exposto a essa variedade (range) de atitudes reativas e sentimentos (...)” (1974, p. 11).

Com relação à tese geral do determinismo, a análise dos sentimentos morais implicados em nossas atitudes reativas, para Strawson, somente nos indica que a falsidade ou verdade desta tese não pode ser baseada na escolha racional sobre como se encara a relação com os outros em termos de perda, enriquecimento ou empobrecimento da vida humana (1974, p. 13). As atitudes reativas são essencialmente reações às qualidades da vontade dos outros em relação a nós, manifestadas nos seus comportamentos: se boa ou má vontade, ou indiferença, ou ausência de preocupação em relação a nós, escreve Strawson (1974, p.14). Assim, o ressentimento, por exemplo, é uma reação à injúria ou indiferença praticada por outros a alguém 9

Por meio desses sentimentos, o ser humano manifesta ao outro como ele interpreta a atitude do outro em relação a si, e vice-versa. A identificação das atitudes reativas parece ser uma forma de se definir a responsabilidade sem precisar-se recorrer a termos como a liberdade e a consciência moral. Pode-se perfeitamente pensar que um indivíduo tem sentimento de ressentimento em relação a uma ação que outro fez a ele. Analogamente, aquele que sente indignação e censura os atos de outro indivíduo considera tais atos moralmente incorretos.

Entretanto, no contexto moral, não se deve esquecer a função das atitudes objetivas. Elas têm um papel importante a ser aqui salientado também, uma vez que Strawson está preocupado com as variações a que as atitudes reativas estão submetidas (1974, p. 6-7). Na nossa vida cotidiana, elas podem ser suspensas por atitudes objetivas. Suspendem-se as atitudes reativas diante de determinados tipos de pessoas, como as deficientes ou incapacitadas. Estas estão impedidas de exercerem seu discernimento moral; por isso, também merecem dos demais um olhar especial.

As modificações a que o ressentimento pode estar sujeito Strawson divide em dois grupos. O primeiro grupo inclui desculpas como "não pretendia", "não havia me dado conta", "não sabia", “não pude evitar", “tinha que fazer", "fui levado a”. Essas atitudes, entretanto, não podem fazer com 
que seja suspenso o sentimento de ressentimento, pois de modo algum fazem que o "agente seja um objeto inapropriado do tipo de demanda por boa vontade e por consideração que são refletidas em nossas atitudes reativas ordinárias “ $(1974$, p. 7$)$.

O segundo grupo é dividido em dois subgrupos. O primeiro subgrupo inclui desculpas do tipo "ele não era o mesmo", "ultimamente ele se encontra sob grande pressão", "estava sob hipnose”. O segundo subgrupo diz respeito a desculpas do tipo "ele/ela é só uma criança", "é um esquizofrênico sem cura", "tem um comportamento compulsivo", "tem uma mente completamente pervertida".

Com relação ao primeiro subgrupo, as desculpas oferecidas pelo agente que causa o ressentimento não podem amenizar o sentimento do que sofreu as ações. Portanto, os sentimentos não estão fora daquilo que pode ser esperado pelas pessoas atingidas pelas ofensas em um contexto de relacionamento interpessoal. O ressentimento por parte daquele que sofreu a ação é perfeitamente adequado, não podendo ser suspenso nem no momento da ação, nem mesmo depois.

No segundo subgrupo, para Strawson, todas nossas atitudes tendem a ser extremamente modificadas (1974, p. 8), pois os agentes são indivíduos com problemas e não tomados como "normais", porque ou apresentam deficiências (deformações e transtornos psíquicos) ou ainda são crianças. A atitude objetiva em relação a esse grupo de pessoas adotadas por quem sofreu algum tipo de ofensa por parte dessas pessoas pode vir também acompanhada de outros sentimentos, que não são os mesmos que ressentimento, gratidão ou condenação moral. São atitudes de medo diante de um psicopata, repulsão diante de um indivíduo fisicamente deformado, compaixão diante de um deficiente ou mesmo amor.

O fato de desenvolvermos e suspendermos atitudes reativas para com os outros nas circunstâncias do segundo subgrupo acima mencionado não impede que adotemos, temporariamente, atitudes objetivas para com adultos normais como uma espécie de refúgio ao envolvimento, ou uma atitude de ajuda, ou mesmo uma atitude de curiosidade intelectual em relação a outras pessoas. Mas sendo humanos, lembra Strawson, não podemos permanecer muito tempo nessa atitude de distanciamento. Percebe-se sempre uma tensão entre as atitudes reativas participantes e as atitudes objetivas (1974, p. 10).

Após apresentar a teoria das atitudes, devo retornar às perguntas colocadas acima na nota seis e no início do tópico 3. A primeira envolve a resposta de Strawson a respeito da influência do determinismo sobre nossas atitudes reativas. Da análise do exemplo do ressentimento, fica mais patente que ele depende mais do "reino da boa vontade" do que do "reino do determinismo" (Strawson, 1974, p. 11). Com relação à possibilidade da verdade da tese do determinismo, não é contraditório pensar-se na perda da importância das atitudes reativas. Mas Strawson está mais inclinado a pensar que isso é "quase inconcebível acontecer", isto é, as atitudes reativas não perderiam seu significado nas relações humanas, porque, como já indiquei anteriormente, estar envolvido em relacionamentos significa estar exposto à diversidade de atitudes e sentimentos. Fora deles, em isolamento, a vida 
dos seres humanos seria improvável. E aqui, essa ênfase de Strawson, parece indicar o enraizamento das nossas atitudes na vida (1974, p. 11).

Uma resposta ao pessimista que desafia o otimista parece já contida na consideração anterior. Não se trata apenas de que seja eficaz proceder como procedemos em nossas relações com os demais, mas, sim, que é o modo como fazemos. Nesse modo parece já haver algo mais do que a eficácia; há uma espécie de obrigação moral dada nos relacionamentos. Por isso, pode-se ver, na resposta ao pessimista, uma naturalização da moral; além disso, a meu ver, a resposta aproxima o pessimista do otimista, pois os conceitos morais continuam a fazer sentido, independentemente de a tese do determinismo ser verdadeira. Faz sentido para as pessoas continuarem agindo da forma como agem umas em relação às outras (Strawson, 1974, p. 22-23).

Outro elemento da resposta de Strawson com respeito à relação das atitudes com a tese do determinismo se refere à relação deste último com as atitudes objetivas de suspender nossos sentimentos. Para o autor, nem adotamos uma atitude objetiva devido à nossa possível crença no determinismo, nem é uma consequência da convicção expressa na forma: "o determinismo nesse caso". Trata-se simplesmente do abandono das atitudes interpessoais ordinárias (Strawson, 1974, p. 13). Em síntese, adotamos as atitudes reativas e as suspendemos não por causa da convicção teórica no determinismo, mas parece fazer sentido no nosso cotidiano. Os sentimentos morais também não perderiam seu significado.

Faltou falar ainda sobre a conciliação, se possível, entre pessimistas e otimistas. O pessimista afirma que os conceitos e as práticas morais só fariam sentido se o determinismo for falso. Mas, com isso, o pessimista acabaria aderindo a uma metafísica - isto é, uma metafísica do agir humano, como eu mencionei no início deste artigo -, indo além dos fatos como os conhecemos. A lacuna que ele cobra do otimista pode ser preenchida dizendo-se que o otimista descreve mal os fatos, ou seja, as atitudes humanas. O pessimista, portanto, também faz o mesmo de outra forma. Para uma reconciliação, Strawson quer assinalar que ambos devem abandonar a superintelectualização dos fatos: o mundo social é tal como são as nossas atitudes e nossa interação. Não existe uma justificativa externa racional, nem é permitida. Nem pessimistas nem otimistas estão aptos a entender isso, diz Strawson (1974, p. 23).

Mesmo o cético tende a intelectualizar as noções de responsabilidade, culpa e condenação. O cético vê a perspectiva do otimista como inadequada e a do pessimista como um libertário vazio. Não encontra alternativa, senão a de declarar os conceitos morais como confusos e afirma que a "condenação é metafísica". Mas, como diz Strawson, "a metafísica está no olho do metafísico" (1974, p. 24).

A que conclusões pode-se chegar após o entendimento do texto de Strawson com relação ao livre-arbítrio e à responsabilidade? 


\section{Conclusões}

Russell (1992) criticou Strawson por não dar uma resposta adequada ao pessimista libertário (por exemplo um kantiano), ou seja, aquele que acredita que a responsabilidade depende da possibilidade de livre-arbítrio ou da liberdade contrafactual. Strawson, segundo Russel, não concorda com os libertários, porque os conceitos usados por ele envolvem uma concepção metafísica.

Penso que a resposta de Strawson parece bastante instigante. Como ele mesmo diz no final de seu texto, muitas ciências hoje pesquisam as atitudes reativas e objetivas que tomamos em nosso cotidiano: a sociologia, a antropologia social, a psicologia, psiquiatria, neurociências, entre outras, o que deveria facilitar o reconhecimento dos fatos básicos de nossas vidas. Não é possível, inclusive, que filósofos olhem para os seres humanos supondo-os desvinculados de tudo que eles próprios estudam com tanto apego $(1974$, p. 25). Sua proposta é corrigir o otimista de sua metafísica do libertarismo (p. 25).

É importante salientar que Strawson, enfatiza o papel das ciências sociais e da psicologia, dizendo que elas, ao investigarem as nossas atitudes, criam uma nova dificuldade: a consciência que temos do conjunto de nossas atitudes reativas tem um aspecto local, isto é, ela está relacionada às diferentes culturas e é relativa ao tempo ou à história. Para ele, isso deveria ser visto com mais cautela e ser reconhecido também que a ausência dessas diferentes formas tornaria impossível entender o que é um sistema de relações e uma sociedade humana (Strawson, 1974, p. 24).

Essa proposta foi realmente importante para a filosofia contemporânea do livre-arbítrio. Arriscaria dizer que o programa da ética de Tugendhat se baseia seriamente na proposta de Strawson: "If we sufficiently, that is radically, modify the view of the optimist, his view is the right one" (Strawson, 1974, p. 24). Tugendhat, como Strawson, imagina que a moralidade deva ser pensada a partir de relações recíprocas ou, em suas palavras, "exigências recíprocas que se expressam em sentenças de dever; esse dever - a 'obrigação' - está calcado nos sentimentos de indignação e culpa e a cada sistema moral pertence um conceito de pessoa moralmente boa" $(2002$, p. 27).

Ora, a meu ver, exigências recíprocas traduzem exatamente nossas atitudes reativas, relacionadas, por exemplo, aos sentimentos de ressentimento e indignação moral. Ressentimento manifesta-se quando alguém é objeto de injúria, injustiça. A indignação é nossa atitude para com aqueles que transgridem um sistema de regras conhecido e aceito socialmente. Qual a correção que Tugendhat precisa fazer, além disso, a Kant, que desconsidera esses sentimentos, uma vez que lhe interessa o ato de julgar pela razão? Rejeitar a razão pura prática e com ela a noção de consciência da lei moral e da liberdade no sentido transcendental. Não tenho espaço para avançar aqui nessas relações entre Strawson e Tugendhat, mas identifico que ambos tentam abandonar a metafísica da ação que faz uso do conceito de vontade livre. Tugendhat acrescenta, em certo sentido mais claramente que Strawson, que "a capacidade para a formação dos sentimentos morais- indignação e 
culpa- como biologicamente dada, caso contrário sistemas sociais de normas não se poderiam de modo algum constituir" (2002, p. 39).

Adriano Brito, tal como afirmei no início, vem seguindo essa trilha de Tugendhat na formulação de uma moral com pressupostos evolucionistas, mas quer alterar pelo menos a base antropológica de Tugendhat. Brito escreve:

As dificuldade com as quais confrontei a tese da teoria antropológica de Tugendhat, que relaciona esse desenvolvimento com o caráter instrumental da linguagem, apontam, pelo menos, para o fato de que a sociabilidade humana não pode estar ancorada no elemento predicativo da linguagem. Nesse sentido, a distinção entre uma associação natural e uma associação moral parece inteiramente inadequada quando pensamos em termos evolutivos.

(..)

Mas se pensamos o fenômeno moral como primordial, no sentido de que a sociabilidade humana é um traço originário que a espécie humana herdou por longa cadeia evolutiva que remonta aos primatas e antes deles aos mamíferos, então temos de buscar não na justificação, mas em outro traço característico da espécie, as bases sobe as quais a sociabilidade se assenta (Brito, 2007b, p. 208) ${ }^{10}$.

Brito propõe uma modificação na tese antropológica de Tugendhat a respeito da linguagem e de seu caráter predicativo, aderindo à idéia de que "quando consideramos relações humanas tipicamente morais e que são fortemente determinadas por afetos, a prioridade da justificação é evidentemente contestada" (Brito, 2007, p. 208). Creio que a perspectiva de Strawson está muito próxima dessa tese, avançando efetivamente em relação à metafísica do livre-arbítrio. $\mathrm{O}$ próprio Strawson responde que o otimista estaria certo, se reconhecesse as atitudes para além dos usos calculativos para propósitos regulativos.

Concordo com Strawson que "nossas práticas não apenas exploram nossa natureza, mas as expressam" (1974. p. 25). Apesar de todas as ciências e de tudo que elas nos apresentam, não sabemos tudo sobre nossas ações e precisamos continuar a viver juntos. Por isso, é importante assumirmos que temos práticas e conceitos e que eles fazem sentido.

Nagel, por exemplo, deixa a questão do determinismo e do livre-arbítrio em aberto ao argumentar que nossas ações podem ser vistas a partir de duas perspectivas: a interna e a externa. Nagel discorda de Strawson com relação à influência que a tese do determinismo teria sobre nossas atitudes reativas. Se pensarmos que, por um lado, do ponto de vista interno, o agente se vê como livre, pois se percebe como decidindo o que fazer, e, por outro lado, do ponto de vista externo, o agente entende que sua ação pode parecer determinada por vários fatores, verificaremos que Nagel acredita que uma informação nova na perspectiva externa não percebida primeiramente pelo agente pode minar sua confiança na liberdade que imaginava experimentar ao tomar sua decisão, afetando também nossas atitudes reativas (Nagel, 2004, p. 206-210). Deve-se dizer que Nagel acredita que temos a tendência de transitar de uma perspectiva para a outra ${ }^{11}$. 
Mas será, então, que a metafísica da vontade de Kant nos ajuda no século XXI? Ou só nos mantém atrelados ao problema de modo antigo, isto é, temos de crer que agimos livremente, quando várias coisas nos dizem que nossa liberdade está reduzida? Posso garantir que isso não é um mal produzido no capitalismo, como muitas mentalidades paranoicas resolvem reduzir os fenômenos de determinação social. A ideia de Kant a respeito da liberdade deveria ser revista, pois, com as ciências modernas, deveríamos mudar nossos conceitos filosóficos.

Pode o naturalismo de Strawson dar conta do problema da liberdade, ou somos apenas determinados a reagir? ${ }^{12}$ Qual a importância da "naturalização" proposta por ele? A naturalização da moral defendida por outros autores, hoje, tem um aspecto positivo: ela aproxima a ética da ciência. Tem um aspecto difícil: diferenciar atitudes naturais de não naturais, sem o uso de uma filosofia transcendental da liberdade. A naturalização ajudaria talvez a saída do pântano da metafísica da liberdade.

Mas se, na ética, teríamos problemas para questionar os critérios de julgamento das normas estabelecidas, na filosofia política perderíamos também a capacidade de discutir os fundamentos da legitimação do poder. Poderíamos resumir a indagação do poder a entender as regras de legitimação do poder estabelecido, sem poder produzir um distanciamento crítico e reflexivo sobre os critérios de legitimação dessas regras? Os conceitos científicos das ciências sociais têm pretensão de indicar certa descrição de fenômenos sociais, mas isso não seria suficiente nem na ética, nem na filosofia política.

A filosofia faz algo que as ciências não têm como meta, ou seja, buscar clareza sobre o uso de seus conceitos e as crenças. Entretanto, Strawson parece certo ao alertar que os filósofos produzem para si também problemas, quando tentam "unificar, teorizar e estabelecer relações para chegar a uma concepção unificada e compreensiva do mundo e da nossa relação com ele. Nesse momento, a mente deixa de prestar atenção à prática, ao papel que os conceitos desempenham realmente na vida (...)" (2002, p. 29). Com isso, muitos filósofos se deixam seduzir por "imagens ou modelos inapropriados, tecendo teorias bizarras e desprovidas de sentido, que são (para repetir a frase de Wittgenstein) 'apenas castelos de cartas"” (Idem, p. 29). 


\section{Notas}

${ }^{1}$ Professor Associado da Universidade Federal de Santa Maria, Doutor em Filosofia pela PUCRS/Universidade de Munique (LMU), Alemanha.

${ }^{2} \mathrm{O}$ determinismo defende a ideia de que todo evento (físico ou ações) no mundo é causado. Os homens tais como os animais e plantas são eventos biológicos. As causas de nossas ações podem ser internas (como decidir tomar água) ou externas (decidir parar diante de um sinal vermelho) (Costa, 2002, p. 267-268).

${ }^{3} \mathrm{O}$ naturalismo ético é definido como aquela perspectiva metaética que afirma: "o conhecimento ético é empírico, portanto o modela conforme o paradigma das ciências naturais. Os conceitos éticos, conforme esta doutrina, dizem respeito aos fenômenos naturais" (Deigh, 2006, p.302). Blackburn (1997, p.262) afirma: "o naturalismo inclui qualquer crença que sustente que a natureza do pensamento ético é exaustivamente compreendida em termos das propensões naturais dos seres humanos". Seria interessante pensar que uma descrição sociológica, ainda que não puramente natural, tende a ser bastante científica, no sentido de empírico e não puramente racional. Não vejo porque não poderia atribuir às descrições das ciências sociais uma forma de "naturalização" ou sociologização do fenômeno moral. O fato é que tais descrições excluiriam a explicações dos fenômenos morais das intuições misteriosas, operações da consciência ou da intervenção divina. As regras e práticas morais passariam a ser vistas como são e não como deveriam ser.

${ }^{4}$ Com relação ao meu colega Adriano Brito, agradeço-o imensamente pelo proveitoso debate que travamos por ocasião do seu curso sobre fundamentação da moral em Santa Maria, em setembro de 2008, no qual ele expôs sua proposta de naturalização da moral. Brito, segundo entendo, nega a pretensão de uma fundamentação objetiva da moralidade, no sentido do programa fundacionalista de Habermas e Apel (Brito, 2007, p. 116), aproximando-se das teses evolucionistas. Com relação aos trabalhos científicos, indico o de Maldonato (2008).

${ }^{5}$ Sobre o conceito de determinismo, ver nota 2.

${ }^{6} 1$ - Qual seria o efeito sobre as atitudes reativas da aceitação da tese geral do determinismo? 2- A aceitação dessa tese conduziria a uma decadência ou repúdio das atitudes por parte dos indivíduos?; 3- Estar-se-ia diante do fim da gratidão, do ressentimento, do perdão, diante do fim das diferentes formas de amor, diante de todos os tipos de antagonismos pessoais?

${ }^{7}$ Não abordarei o problema do solipcista moral (1962, p. 15), que é só uma possibilidade conceitual.

${ }^{8}$ É importante lembrar, sobre isso, que as pesquisas realizadas, nos anos 70, pelo neurocientista Benjamim Libet coincidem com as intuições filosóficas de Strawson, ao afirmar que a decisão voluntária se daria, sem a contribuição da consciência que decide o resultado da ação, por meio de facilitações ou inibições. A consciência, para Libet, não daria início à ação voluntária. Além disso, na origem da intenção e da realização da ação, há memória emocional, e esta não seria controlada pela consciência (Maldonato, 2008, p. 91).

${ }^{9}$ Strawson, entretanto, alerta que há um aspecto enganador tanto no conceito de atitudes como na sua descrição, mas quer manter o nome pelo seu aspecto sugestivo.

${ }^{10}$ Adriano Brito também defendeu, em outro texto (2007a), que: 1) há impossiblidade da objetividade da justificação moral, pois toda justificação está baseada em preferências ou razões subjetivas; 2) a pretensão de validade de nossas razões depende do convencimento dos outros de nossa tese.

${ }^{11}$ Para Nagel, há a questão da impossibilidade do ponto de vista externo, ou seja, um ponto cego na perspectiva externa do agente: jamais sabemos tudo. Se fosse possíve,l anular-se-ia o livre-arbítrio ou estaríamos impedidos da subjetividade?

${ }^{12}$ W. Dilthey no séc. XIX, afirmou que com o processo de evolução social os nossos impulsos mais naturais foram transformando-se em sentimentos morais construídos socialmente. Até mesmo as instituções são produto de uma Entlastung (descarregamento) da nossa psicologia natural depositando nas instituições tarefas de dar conta a sentimentos humanos. A. Gehlen, no séc. XX retomou esse conceito reforçando o papel do descarregamento na sua teoria. 


\section{Referências}

ALMEIDA, G. A. Liberdade e moralidade segundo Kant. In.: Analytica, v. 2, n. 1, 1997, p. 175202.

BLACKBURN, S. Dicionário Oxford de Filosofia. Rio de Janeiro: Jorge Zahar, 1997.

BRITO, A. N. de. Sobre a fundamentação da moral. In.: . (Org.). Questões de fundamentação. Brasília: EdUnB, 2007a. p. 99-118.

BRITO, A. Moral, justificação e evolução em Ernst Tugendhat. In.: DALL'AGNOL, G. (Org.). Verdade e respeito. Florianópolis: Ed. da UFSC, 2007b.

DEIGH, J. Ética. In.: AUDI, R. (ed.). Dicionário de Filosofia de Cambridge. São Paulo: Paulus, 2006.

ESHLEMAN, A. Moral Responsibility. In.: Stanford Encyclopedia of Philosophy. 2004. Disponível em: http://plato.stanford.edu/entries/moral-responsibility/. Acesso em: 30 jan. 07. p. 287-302.

FRANKENA, W. K. Ética. Rio de Janeiro: Zahar, 1969.

MALDONATO, M. Rumo a uma Ciência do Livre-Arbítrio. In.: Scientific American. Brasil.v. 6, n. 76, p. 88-95.

STRAWSON, P. F. Análise e metafísica. São Paulo: Discurso Editorial, 2002.

STRAWSON, P. F. Freedom and Resentment. In.: . Freedom and Resentment. USA: Methuen, 1974.

TUGENDHAT, E. Como devemos entender a moral? In.: ROHDEN, V. (Org.). Não somos de arame rígido. Canoas: Ed ULBRA, 2002

WILLIAMS, G. A. Responsibility. In.: Internet Encyclopedia of Philosophy. 2006. Disponível em: http://www.iep.utm.edu/r/responsi.htm. Acesso em: 30 jan. 07 